\title{
Lessons from modular approach to training for minimally invasive aortic valve replacement: implications for training and outcome
}

\author{
Umair Aslam*, Joseph George, Pankaj Kumar \\ From World Society of Cardiothoracic Surgeons 25th Anniversary Congress, Edinburgh \\ Edinburgh, UK. 19-22 September 2015
}

\section{Background/Introduction}

Minimally-invasive Aortic Valve Replacement (mini-AVR) is being increasingly adopted in clinical practice. Training can be a challenge due to the inherent difficulties of limited surgical exposure. We analysed individual trainee experience in our institutional undergoing mini-AVR training within a series of our cases where all AVRs are routinely undertaken by this approach.

\section{Aims/Objectives}

We assessed the impact and outcome on training in miniAVR in our centre at both the trainee cohort and individual trainee levels. We assessed the complication rates between trainees and consultant surgeon undertaking mini-AVR in the context of challenging surgical access.

\section{Method}

A single consultant surgeon undertook minimally-invasive aortic valve replacement for all isolated first-time aortic valve replacement, without any selection. Operative records and cardiac surgery database of all patients who had undergone mini-AVR between 2006-2015 were retrieved. Patient demographics, premorbid status, operating surgeon, operative details and outcome were evaluated. We constructed learning curves of individual trainees and compared. Part-procedures were defined and enumerated, and individual experience over time was plotted. Risk stratification was also analysed. $\mathrm{p}<0.05$ was defined to be statistically significant.

\section{Results}

171 mini-AVRs were undertaken between 2006 and 2015. We defined a case as all parts being undertaken by the operator. Mini-AVR was divided into nine component part-procedures including mini-sternotomy, cannulation, aortotomy, decalcification, implantation, aortotomy closure, de-airing and weaning, decannulation and sternotomy closure. $13 \%$ of cases $(n=23)$ were undertaken by trainees. The proportion of part-procedures undertaken by trainees varied between 13\% (all part-procedures) to $87 \%$ (single part-procedures) of all cases. The learning curve of five trainees with the highest operative numbers were plotted. The learning curve of a single trainee over time was plotted in part-procedures. Logistic euroSCORE was not significantly different between trainees and consultants, however trainees took longer bypass and cross-clamp times.

\section{Discussion/Conclusion}

We demonstrate detailed learning curves and outcomes comparison in learning minimally-invasive aortic valve replacement. The challenge in mini-AVR is the access mini-sternotomy and cannulation, which is the focus in our training programme.

Published: 16 December 2015

doi:10.1186/1749-8090-10-S1-A292

Cite this article as: Aslam et al: Lessons from modular approach to training for minimally invasive aortic valve replacement: implications for training and outcome. Journal of Cardiothoracic Surgery 2015 10(Suppl 1): A292.

Cardiothoracic Surgery, Morriston Hospital, Swansea, SA6 6NL, UK 